\title{
Petroleum degradation by Pseudomonas sp. ZS1 is impeded in the presence of antagonist Alcaligenes sp. CT10
}

Jibei Liang ${ }^{1}$, Tao Cheng ${ }^{1}$, Yi Huang ${ }^{1}$ and Jianhua Liu ${ }^{1,2^{*}}$ (D)

\begin{abstract}
Enhanced bioremediation is a favorable approach for petroleum pollutant cleanup, which depends on the growth of oil-eating microorganisms. In this study, we show that, by using the modified T-RFLP (mT-RFLP) methodology, one of the four major microbial populations derived from oil sludge has failed to propagate in MS medium supplemented with $2 \%$ yeast extract (YE). rDNA sequence-based analysis indicated that the four populations were Donghicola sp. CT5, Bacillus sp. CT6, Alcaligenes sp. CT10, and Pseudomonas sp. ZS1. Four purified strains grow well individually in MS medium supplemented with $2 \% \mathrm{YE}$, suggesting that ZS1 growth is antagonized by other strains. Co-growth analysis using mT-RFLP methodology and plate inhibitory assay indicated that ZS1 exhibited antagonistic effect against CT5 and CT6. On the other hand, co-growth analysis and plate inhibition assay showed that CT10 antagonized against ZS1. To investigate the potential compounds responsible for the antagonism, supernatant of CT10 culture was subjected to GC-MS analysis. Analysis indicated that CT10 produced a number of antimicrobial compounds including cyclodipeptide c-(L-Pro-L-Phe), which was known to inhibit the growth of Pseudomonas sp. Growth test using the purified C-(L-Pro-L-Phe) from CT10 confirmed its inhibitory activity. We further showed that, using both gravimetric and GC analysis, CT10 antagonism against the oil-eating ZS1 led to the diminishing of crude oil degradation. Together, our results indicate that bioremediation can be affected by environmental antagonists.
\end{abstract}

Keywords: Alcaligenes sp., Antagonism, Bioremediation, Cyclodipeptide, Oil-degrading microorganism, Pseudomonas sp.

\section{Introduction}

Petroleum leakage is a major threat to land and marine environment (Holliger et al. 1997). Physical methods involving removal of solid and liquid pollutants are tedious and expensive; and chemical methods using chemically synthesized surfactants can cause secondary pollution (Kanaly and Harayama 2010; Murphy et al. 2005). Enhanced bioremediation method using indigenous oil-eating microorganisms and biosurfactants is believed to be a favorable method for oil spill cleanup (Patowary et al. 2016; El-Bestawy et al. 2014; Karamalidis

\footnotetext{
*Correspondence: liujh2013@zju.edu.cn

1 Ocean College, Zhejiang University, Marine Science Building \#379, Zhoushan Campus, 1 Zheda Road, Dinghai District, Zhoushan 316000, ZJ, China

Full list of author information is available at the end of the article
}

et al. 2010; Al-Mailem et al. 2017; Varjani and Upasani 2016).

Many studies have focused on the physical and chemical conditions at the pollution sites that affect the performance of enhanced bioremediation (Díaz-Ramírez et al. 2003; Venosa and Zhu 2003). Physical conditions such as temperature and salinity affect the growth of many microorganisms. Similarly, chemical conditions include mineral salts and pollutant toxic compounds also influence the growth of various microorganisms. Hence, indigenous isolates of microorganisms are advantageous for enhanced bioremediation (Patowary et al. 2016; ElBestawy et al. 2014). However, it remains unclear whether antagonism between microorganisms including the oileating ones will affect the cleanup of oil pollutants. 
Antagonisms between microorganisms are not uncommon. Many antibiotics are discovered through the observation of compounds that are nontoxic to humans but exhibit antagonistic effect against pathogenic microbes. The most well-known example is the discovery of penicillin by Fleming (Fleming 1929). Before long, Waksman has established the plate inhibitory method for systematic screening for soil microbes, especially the Actinomyces spp. that are capable of inhibiting pathogenic microbes (Waksman and Woodruff 1940). A number of antibiotics were successfully identified and characterized including streptomycin and neomycin that have extensively been applied to the treatment of numerous infectious diseases (Waksman and Woodruff 1940).

Restriction fragment length polymorphism (or RFLP) analysis of amplified rDNA allows identification of microorganisms such as mycobacterium species (Vaneechoutte et al. 1993). Terminal fluorescence labeled RFLP (T-RFLP) analysis is a method for identification of mixed microbial populations with the help of DNA sequencer (Liu et al. 1997). We have previously modified the T-RFLP (mT-RFLP) method by replacing DNA sequence gel with mini-PAGE gel to study dynamic change of microbial populations without the need for DNA sequencer, an equipment uncommon in many biology laboratories (Cheng et al. 2017). By using the mT-RFLP analysis, we have isolated the rhamnolipidproducing oil-eating Pseudomonas sp. ZS1 strains from the mixed culture of petroleum sludge-originating microbes cultivated in MS medium supplemented with $2 \%$ glucose (Cheng et al. 2017).

In this study, we show that the growth of Pseudomonas sp. ZS1 is suppressed in the mixed culture of sludge-originating microbes in medium without glucose. Co-growth and plate inhibition analyses reveal that an Alcaligenes sp. CT10 strain exhibits antagonistic effect against Pseudomonas sp. ZS1. GC-MS analysis shows that a number of antimicrobial compounds including cyclodipeptide c-(L-Pro-L-Phe) present in supernatant of CT10 culture. Both gravimetric and GC analyses show that CT10 impedes the oil-degradation by ZS1, implying that antagonisms between environmental microorganisms can affect the outcome of bioremediation.

\section{Materials and methods}

\section{Strains, DNA, and cultures}

Petroleum sludge was collected in April 2016 at Sanjiang Ferry Terminal, Zhoushan, Zhejiang province, China. Microbial strains were resuspended and maintained in mineral salt (MS) medium (1 L contains: $0.6 \mathrm{~g} \mathrm{Na}_{2} \mathrm{HPO}_{4}$, $0.2 \mathrm{~g} \mathrm{KH}_{2} \mathrm{PO}_{4}, 4.0 \mathrm{~g} \mathrm{NaNO}_{3}, 0.3 \mathrm{~g} \mathrm{MgSO}_{4}, 0.01 \mathrm{~g} \mathrm{CaCl}_{2}$, $0.01 \mathrm{~g} \mathrm{FeSO}_{4}, 1 \mathrm{~g}$ or $0.1 \%$ yeast extract or YE) (Zajic and Supplison 1972). For propagation, strains were cultivated in glass conical flask at $30{ }^{\circ} \mathrm{C}$ in MS medium supplemented with $2 \%$ YE or $1 \%$ crude oil. Cell growth was monitored by either colorimetric (optical density at the wavelength of $600 \mathrm{~nm}$ ) or gravimetric methodologies (cell dry weight). All measurements were performed in triplicate, unless otherwise stated.

Pseudomonas sp. ZS1, Alcaligenes sp. CT10, Donghicola sp. CT5 and Bacillus sp. CT6 strains were deposited in the China General Microbiological Culture Collection Center with the accession numbers of CGMCC-13460, CGMCC-1.16509, CGMCC-1.16485 and CGMCC-1.16486 (respectively) and whose 16S rDNA sequences were deposited in NCBI GenBank with the accession number of KY437088, KY437091, KY437089 and KY437090, respectively.

Oligonucleotide DNA sequences 27F, 5'-AGAGTT TGATCMTGGCTCAG- $3^{\prime}$ and 1492R, $5^{\prime}$-TACGGYTAC CTTGTTACGACTT-3' (Moreno et al. 2002) used in PCR amplification of $16 \mathrm{~S}$ rDNA were purchased from BGI (BGI, Shenzhen, China).

\section{Preparation of genomic DNA and PCR analysis}

To obtain microbial genomic DNA for PCR amplification, mixed or clonal microbial cultures were pelleted by centrifugation and the resulting pellet was resuspended in lysis solution using Genomic DNA Extraction kit (Axygen Scientific Inc., Tewksbury, MA, USA) and extracted according to the manufacturer's instruction. The 16S rDNA fragment was PCR amplified by using the microbial genomic DNA as template and 16S rDNAspecific primers 27F and 1492R (Moreno et al. 2002). The PCR condition was set as follows: after the initial denaturation at $95{ }^{\circ} \mathrm{C}$ for $5 \mathrm{~min}, 30$ cycles of $95{ }^{\circ} \mathrm{C}$ for $30 \mathrm{~s}$, $55^{\circ} \mathrm{C}$ for $30 \mathrm{~s}$, and $72{ }^{\circ} \mathrm{C}$ for $90 \mathrm{~s}$, and a final extension at $72{ }^{\circ} \mathrm{C}$ for $10 \mathrm{~min}$. The resulting PCR fragment was subjected to sequencing analysis in BGI (BGI, Shenzhen, China) and compared with NCBI's nucleotide sequences using BLAST tools (http://www.ncbi.nlm.nih.gov).

\section{Modified T-RFLP or mT-RFLP analysis}

To examine the dynamic change of mixed microbial populations under various growth conditions, we modified the T-RFLP method (Liu et al. 1997) by using the mini-PAGE gel instead of sequencing gel. In brief, the $16 \mathrm{~S}$ rDNA fragments were PCR amplified on genomic DNA as template derived from microbial populations using the 27F-fluorescence labeled and 1492R unlabeled primers. The resulting fragments were subjected to HhaI (New England Biolabs Inc., Ipswich, MA, USA) digestion and $8 \%$ mini-PAGE gel electrophoresis. Fluorescence signals were captured using the Gel Imaging System Tanon 5200 (Tanon Scientific Inc., Shanghai, China) with a SybrGreen fluorescence channel. 


\section{Co-growth assay}

Equal amount of overnight cultures was mixed and inoculated to fresh medium to a concentration of $0.1 \mathrm{OD}_{600}$. Cell populations at various time points during growth were examined using mT-RFLP analysis (see above). Gel image was recorded using the Gel Imaging System Tanon 5200 (Tanon Scientific Inc.).

\section{Preparation of supernatant crude extract for growth inhibition analysis}

Growth inhibitory factors in cell-free supernatant of Pseudomonas sp. ZS1 and Alcaligenes sp. CT10 cultures were prepared by following the methods previously reported by Zhang et at. (Zhang and Miller 1992) and Bharali et al. (Bharali et al. 2011), respectively. In brief, supernatant of ZS1 culture was acidified to $\mathrm{pH} 2.0$ using $\mathrm{HCl}$. The resulting precipitate was collected by centrifugation at 13,400g for $30 \mathrm{~min}$ and dissolved in bicarbonate (pH 8.6) and extracted twice with chloroform-ethanol $(2: 1 \mathrm{v} / \mathrm{v})$ solution. The organic phase was evaporated and the resulting paste or crude extract was used in growth inhibition assay. Likewise, supernatant of CT10 culture was acidified to $\mathrm{pH} 2.0$ using $\mathrm{HCl}$ and kept at $4{ }^{\circ} \mathrm{C}$ overnight. The turbid supernatant was extracted twice with an equal volume of ethyl acetate and collected through a separating funnel. Subsequently, the organic phase was evaporated and the resulting paste or crude extract was used in growth inhibition test and GC-MS analysis for bioactive compounds.

\section{Plate inhibitory assay}

To examine the growth inhibitory activities of the supernatant, crude extract (see above) of supernatants was dissolved in chloroform to a final concentration of $50 \mathrm{mg} \mathrm{mL}^{-1}$. Filter discs containing $20 \mu \mathrm{L} 50 \mathrm{mg} \mathrm{mL}^{-1}$ supernatant crude extract were placed on top of MS agar plates that were inoculated with the test strains. As control, filter discs containing $20 \mu \mathrm{L}$ solvent chloroform and $20 \mu \mathrm{l} 50 \mathrm{mg} \mathrm{mL}^{-1}$ ampicillin in water were also placed on the same plate. Images were taken 1-3 days after incubation at $30{ }^{\circ} \mathrm{C}$.

\section{GC-MS analysis of compounds extracted from supernatant} of Alcaligenes sp. CT10 culture

The compounds extracted from supernatant of Alcaligenes sp. CT10 culture (CEAC) was analyzed by gas chromatography coupled with mass spectrophotometer (GC-MS). $1 \mu \mathrm{L}$ of CEAC was directly injected into the injection port of gas chromatograph (Shimadzu 2010Plus GC system, Shimadzu Co., Tokyo, Japan) coupled with a mass spectrometer system (MS) (Shimadzu QP2020 with quadrupole analyzer). The GC was operated on an Rtx-5MS GC column $(30 \mathrm{~m} \times 0.25 \mathrm{~mm}$, id. with $0.25 \mu \mathrm{m}$ film thickness of 5\%-phenyl-methylpolysiloxane) (Restek Co., Bellefonte, PA, USA) and helium (purity 99.999\%) was used as the carrier gas. The temperature of the injection port was set to $250{ }^{\circ} \mathrm{C}$ while the sample injection was made in splitless mode with a purge flow $50 \mathrm{~mL} \mathrm{~min}{ }^{-1}$ for $1 \mathrm{~min}$. The temperature program was started with an initial temperature at $50{ }^{\circ} \mathrm{C}$ and held for $2 \mathrm{~min}$ at this temperature, then $6{ }^{\circ} \mathrm{C} \mathrm{min}{ }^{-1}$ to $300{ }^{\circ} \mathrm{C}$ for $20 \mathrm{~min}$

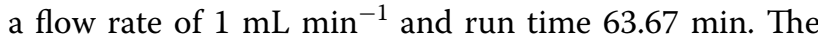
mass spectrometer was operated in electron ionization (EI) mode with the ion source temperature at $230{ }^{\circ} \mathrm{C}$. The MS quad temperature was set at $150{ }^{\circ} \mathrm{C}$. The electron energy was $70 \mathrm{eV}$. Full-scan MS data were acquired in the range of $50-500 \mathrm{~m} / \mathrm{z}$ to obtain the fragmentation spectra of CEAC. The LabSolutions (Shimadzu Co.) was used to determine all the peaks in raw GC chromatogram. Library search was done for all the peaks using the National Institute of Standards and Technology NIST/ EPA/NIH (NIST 14 Library). All results were combined into a single peak table (Table 1 ).

\section{Purification of bioactive compounds}

The oily yellow residue $(2.7 \mathrm{~g})$ was subjected to column chromatography on a silica gel column (Qingdao Haiyang Chemical Co., Ltd., Qingdao, China) pre-equilibrated with dichloromethane and eluted with a gradient solvent system dichloromethane-methanol (v/v, 20:1 to 0:100). Seven fractions were collected and tested for antimicrobial potential with plate inhibitory assay. Fraction 4 (1.1 g), showing inhibitory activity against Pseudomonas sp. ZS1, was subjected to silica gel column chromatography and eluted with hexane-dichloromethane (3:1 $\mathrm{v} / \mathrm{v})$. Repeated chromatography led to pure compound 1 (10 mg).

\section{Structure elucidation of bioactive compounds}

The structure of the compound 1 was determined using NMR spectroscopy (Bruker DRX 500 NMR instrument, Bruker, Rheinstetten, Germany). $\mathrm{CDCl}_{3}$ (Deuterated chloroform) was used as solvent in ${ }^{1} \mathrm{H}$ and ${ }^{13} \mathrm{C}$ NMR experiments. ${ }^{1} \mathrm{H}$ NMR spectra were recorded in $\mathrm{CDCl}_{3}$ using tetramethylsilane (TMS) as internal standard at 500 and $400 \mathrm{MHz},{ }^{13} \mathrm{C} \mathrm{NMR}$ spectra were recorded at 125 and $100 \mathrm{MHz}$, chemical shifts are given in parts per million and coupling constants in $\mathrm{Hz}$.

\section{Determination of minimum inhibitory concentrations (MICs)}

To investigate the minimum inhibitory concentration of compound 1 or cyclodipeptide c-(L-Pro-L-Phe), we followed the protocol described Singh-Babak et al. (Singh-Babak et al. 2012). In brief, the compound and ciprofloxacin (Aladdin Industrial Co. Shanghai, China) 
Table 1 Compounds derived from supernatant of Alcaligenes sp. CT10 cultures

\begin{tabular}{|c|c|c|c|c|c|c|}
\hline No. & $\mathrm{RT}^{\mathrm{a}}$ & Compound name & M.W. & Formula & $\% \mathrm{Pk}^{\mathbf{b}}$ & Comment $^{c}$ \\
\hline 1 & 5.44 & Ethylbenzene & 106 & $\mathrm{C}_{8} \mathrm{H}_{10}$ & 0.86 & - \\
\hline 2 & 5.63 & 1,4-Dimethylbenzene & 106 & $\mathrm{C}_{8} \mathrm{H}_{10}$ & 2.35 & - \\
\hline 3 & 5.67 & 1,3-Dimethylbenzene & 106 & $\mathrm{C}_{8} \mathrm{H}_{10}$ & 0.7 & - \\
\hline 4 & 6.12 & Styrene & 104 & $\mathrm{C}_{8} \mathrm{H}_{8}$ & 5.86 & - \\
\hline 5 & 11.87 & n-Hendecane & 156 & $\mathrm{C}_{11} \mathrm{H}_{24}$ & 6.76 & - \\
\hline 6 & 15.66 & 2(3H)-benzofuranone & 134 & $\mathrm{C}_{8} \mathrm{H}_{6} \mathrm{O}_{2}$ & 2.79 & $\begin{array}{l}\text { Insecticidal } \\
\text { Fan et al. (2008) }\end{array}$ \\
\hline 7 & 16.15 & Benzeneacetic acid & 136 & $\mathrm{C}_{8} \mathrm{H}_{8} \mathrm{O}_{2}$ & 34.54 & $\begin{array}{l}\text { Antimicrobial } \\
\text { Zhu et al. (2011) }\end{array}$ \\
\hline 8 & 19.96 & Anthranilic acid & 137 & $\mathrm{C}_{7} \mathrm{H}_{7} \mathrm{NO}_{2}$ & 3.16 & $\begin{array}{l}\text { Antiendotoxic } \\
\text { Fang et al. (2005) }\end{array}$ \\
\hline 9 & 20.37 & trans-2-Decenoic acid & 170 & $\mathrm{C}_{10} \mathrm{H}_{18} \mathrm{O}_{2}$ & 9.44 & - \\
\hline 10 & 26.16 & Tributyl phosphate & 266 & $\mathrm{C}_{12} \mathrm{H}_{27} \mathrm{O}_{4} \mathrm{P}$ & 7.69 & - \\
\hline 11 & 31.70 & $\begin{array}{l}\text { Hexahydro-3-(1-methylethyl)pyrrolo[1,2-a]pyrazine- } \\
\text { 1,4-dione }\end{array}$ & 210 & $\mathrm{C}_{11} \mathrm{H}_{18} \mathrm{~N}_{2} \mathrm{O}_{2}$ & 4.9 & $\begin{array}{l}\text { Antimicrobial, antifungal } \\
\text { Yan et al. (2004) } \\
\text { Rhee (2004) }\end{array}$ \\
\hline 12 & 32.06 & $\begin{array}{l}\text { Hexahydro-3-(1-methylethyl)pyrrolo[1,2-a]pyrazine- } \\
\text { 1,4-dione }\end{array}$ & 210 & $\mathrm{C}_{11} \mathrm{H}_{18} \mathrm{~N}_{2} \mathrm{O} 2$ & 6.84 & $\begin{array}{l}\text { Antimicrobial, antifungal } \\
\text { Borthwick (2012), Campbell et al. (2009) } \\
\text { Yan et al. (2004) } \\
\text { Rhee (2004) }\end{array}$ \\
\hline \multirow[t]{2}{*}{13} & 40.12 & $\begin{array}{l}\text { Hexahydro-3-(phenylmethyl)pyrrolo[1,2-a]pyrazine- } \\
\text { 1,4-dione }\end{array}$ & 244 & $\mathrm{C}_{14} \mathrm{H}_{16} \mathrm{~N}_{2} \mathrm{O}_{2}$ & 1.81 & $\begin{array}{l}\text { Antimicrobial, antifungal } \\
\text { Kumar et al. (2013) }\end{array}$ \\
\hline & & & & & 87.52 (Total) & \\
\hline
\end{tabular}

a RT for retention time in minute

b \%Pk for percent of peak area

c Comment includes bioactivity and references

was subjected to twofold serial dilution from 1025 to $1 \mu \mathrm{g} \mathrm{mL}^{-1}$ in $100 \mu \mathrm{L}$ of Luria-Bertani (LB) broth (Bertani 1951) using multiwell plate in duplicate. Fresh overnight culture of ZS1 in LB was diluted to a final concentration of $5 \mathrm{E}-04 \mathrm{OD}_{600}$. The resulting culture of $100 \mu \mathrm{L}$ was transferred and mixed with twofold serial dilutions of compound or ciprofloxacin. The plate was incubated at $30{ }^{\circ} \mathrm{C}$ for $24 \mathrm{~h}$ prior to OD measurement. The minimum concentration of the well without bacterial growth was defined as minimum inhibitory concentration (MIC). The MIC of compound 1 and Ciprofloxacin was 32 and $2 \mu \mathrm{g} \mathrm{mL}^{-1}$, respectively.

\section{Gravimetric analysis of crude oil consumptions}

To estimate the consumption of crude oil by Pseudomonas sp. ZS1 in presence and absence of Alcaligenes sp. CT10, cell mass and crude oil quantity (maximum level was set to $100 \%$ ) were determined in microbial cultures (i.e., ZS1, CT10, and mixture of ZS1 and CT10) in $180 \mathrm{rpm}$ shake flask at $30^{\circ} \mathrm{C}$ containing MS medium supplemented with $1 \%$ crude oil. Both cell mass and crude oil mass were determined gravimetrically. In brief, cells were pelleted from $50 \mathrm{~mL}$ culture by centrifugation, resuspended in $0.5 \mathrm{~mL}$ MS medium, and transferred to filter paper for drying in an oven. Dried filter paper was weighted prior to and after addition of cells. Crude oil mass was determined after removal of cell mass by centrifugation. Oil in supernatant was extracted using hexane that was evaporated prior to weighting. Samples at 36 days were also analyzed using GC-MS and GC analyses.

\section{Gas chromatography analysis of crude oils in cultures of CT10 and ZS1}

The composition of crude oils was analyzed using the GC-MS methodology similar to the analysis of compounds in supernatant of CT10 cultures (see above). To analyze level-changes of individual molecules in crude oils extracted from supernatant of cultures, $1 \mu \mathrm{L}$ of sample was directly injected into the injection port of gas chromatograph (Shimadzu Co.) equipped with flame ionization detector (FID) and Rtx-5 column $(30 \mathrm{~m} \times 0.32 \mathrm{~mm}$, id. with $0.25 \mu \mathrm{m}$ film thickness) (Restek Co., Bellefonte, PA, USA). The sample injection was made in split mode and the split ratio was 20:1. The temperature of the injection port and detector temperature were set to 280 and $305^{\circ} \mathrm{C}$, respectively. The temperature program was started with an initial temperature at $70{ }^{\circ} \mathrm{C}$ 
and held for $2 \mathrm{~min}$ at this temperature, then $25{ }^{\circ} \mathrm{C} \mathrm{min}-1$ to $140{ }^{\circ} \mathrm{C}$, followed by an additional increase of $3{ }^{\circ} \mathrm{C}$ $\min ^{-1}$ to $240{ }^{\circ} \mathrm{C}$, then $10{ }^{\circ} \mathrm{C} \min ^{-1}$ up to $300{ }^{\circ} \mathrm{C}$, held for $15 \mathrm{~min}$. The total duration of the temperature program was $59.13 \mathrm{~min}$. Nitrogen was used as carrier gas, and its flow rate was $30 \mathrm{~mL} \mathrm{~min}^{-1}$. Hydrogen gas flow rate and air flow rate were 40 and $400 \mathrm{~mL} \mathrm{~min}^{-1}$, respectively. Level of individual compositions was estimated based on the peak area and degradation rate was based on the formula below:

$$
\mathrm{DEG} \%=\left(\mathrm{LEVEL}_{\mathrm{ctl}}-\mathrm{LEVEL}_{\mathrm{smp}}\right) / \mathrm{LEVEL}_{\mathrm{ctl}}
$$

where $\mathrm{DEG} \%$ is the rate of degradation, $\mathrm{LEVEL}_{\mathrm{ctl}}$ and LEVEL $_{\text {smp }}$ are compound level in control and in sample, respectively.

\section{Results}

\section{Analysis of population dynamics in mixed culture derived} from oil sludge

The oil sludge-derived mixed microorganisms were suspended in MS medium and subsequently inoculated into the fresh MS medium supplemented with $2 \%$ yeast extract (YE) (see "Materials and methods"). The growth of the mixed culture was monitored by colorimetric methodology $\left(\mathrm{OD}_{600}\right)$ (Fig. 1a). To investigate the microbial population dynamics, total DNA was extracted from the culture at various time points during growth and then subjected to the modified T-RFLP (mT-RFLP) analysis (see "Materials and methods").

In this analysis, each RFLP fragment would represent a unique microbial population. We found that four populations, namely CT5, CT6, CT10, and ZS1, were present in the initial culture (at $0 \mathrm{~h}$ time point). However, $50 \mathrm{~h}$ after growth, only three populations CT5, CT6, and CT10 remained (Fig. 1b). Strains from the four major populations were isolated from the initial culture $(0 \mathrm{~h})$ based on the mT-RFLP patterns. Analysis of the $16 \mathrm{~S}$ rDNA sequences indicated that the four strains were Donghicola sp. CT5, Bacillus sp. CT6, Alcaligenes sp. CT10, and Pseudomonas sp. ZS1 (Fig. 1c). Of these four strains, Pseudomonas sp. ZS1 was previously isolated from the oil sludge (Cheng et al. 2017). Given that all four major strains grew well individually in MS medium supplemented with $2 \%$ YE (Additional file 1: Figure S1), this result suggested that $\mathrm{ZS1}$ growth was suppressed by one of the CT5, CT6, and CT10 strains.

\section{Antagonisms found between the four major populations}

To investigate the potential antagonism between ZS1 and CT5, CT6, or CT10, co-growth analysis was performed (see "Materials and methods"). In the co-growth analysis between ZS1 and CT5 or CT6 using mT-RFLP method to monitor change of populations, we found that
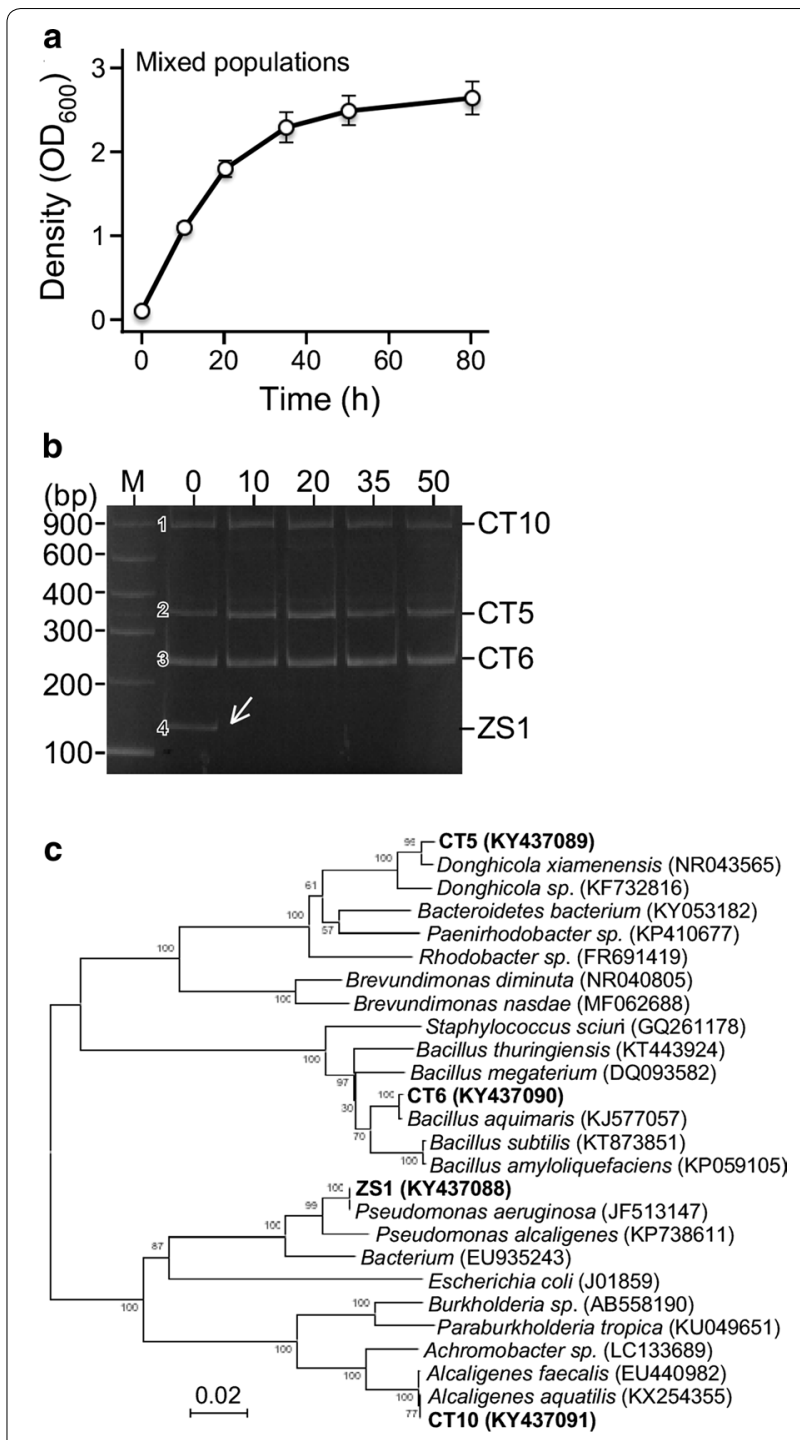

Fig. 1 Growth of ZS1 strain is inhibited by other sludge-derived microbes in MS medium supplemented with 2\% YE. a Growth curve of the sludge-derived mixed culture in MS medium with $2 \%$ YE. $\mathbf{b}$ Dynamic change of microbial populations in mixed culture. Image of mT-RFLP analysis. Four major microbial populations in the initial culture (at $0 \mathrm{~h}$ ) are numbered. c Phylogenetic tree analysis based on $16 \mathrm{~S}$ rDNA sequences. The tree is built using CLUSTALW and NJPLOT. Sequence accession number of all strains is shown in parentheses

ZS1 inhibited the growth of CT5 and CT6, rather than the reverse (Additional file 1: Figure S2). Plate inhibitory assay indicated that this was a result of rhamnolipid (Additional file 1: Figure S2). On the other hand, in the co-growth analysis between ZS1 and CT10, mT-RFLP analysis indicated that ZS1 population failed to growth at $10 \mathrm{~h}$ after co-growth (Fig. 2a, b). This was the first time to observe that Alcaligenes sp. exhibited antagonistic activity against Pseudomonas sp. To investigate whether 


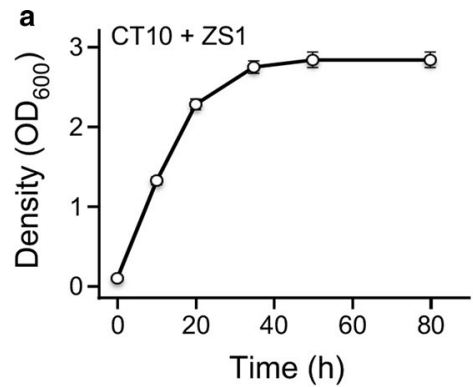

b

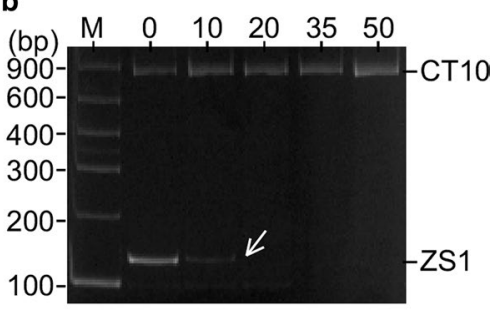

c

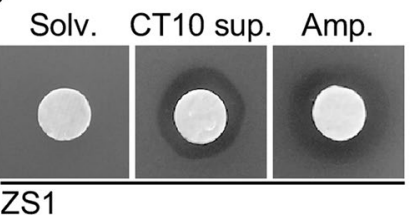

Fig. 2 Alcaligenes sp. CT10 antagonizes against Pseudomonas sp. ZS1. a Growth curve of the mixed CT10 and ZS1 cultures. b Dynamic change of $\mathrm{CT} 10$ and ZS1 populations in mixed culture. Arrow indicates the point that the population diminished. $\mathbf{c}$ Plate halo assay showing that the growth of ZS1 is inhibited by supernatant extract derived from $\mathrm{CT} 10$ cultures

inhibition factors against ZS1 were secreted into the medium from CT10, supernatant extract of CT10 culture was prepared (see "Materials and methods"). Plate inhibition assay using supernatant extract from CT10 culture on a disc paper indicated that it exhibited apparent inhibitory effect against ZS1 (Fig. 2c). This result indicated that Alcaligenes sp. CT10 secreted the unknown factor that antagonized against Pseudomonas sp. ZS1.

\section{Cyclodipeptide c-(L-Pro-L-Phe) from CT10 displays inhibitory activity against ZS1}

To investigate the potential antagonistic factors against ZS1, supernatant extract derived from CT10 culture was subjected to GC-MS analysis (see "Materials and methods"). The result indicated that 13 major peaks or compounds were detected (Fig. 3a). Of the 13 peaks, peak 11 and 12 represented the same molecule cyclodipeptide c-(Pro-Leu), suggesting that the two stereoisomers c-(D-Pro-L-Leu) and c-(L-Pro-L-Leu) were separated (Fig. 3b). To this end, a number of compounds that were shown to be bioactive such as insecticidal (peak 6 , 2(3H)-benzofuranone) (Fan et al. 2008), antiendotoxic (peak 8, anthranilic acid) (Fang et al. 2005), antimicrobial and antifungal (peak 7, phenylacetic acid; peak 11 and 12, hexahydro-3-(1-methylethyl) pyrrolo[1,2-a]pyrazine-1,4-dione; peak 13, hexahydro-3-(phenylmethyl) pyrrolo[1,2-a]pyrazine-1,4-dione) (Fan et al. 2008; Zhu et al. 2011; Kumar et al. 2013; Yan et al. 2004; Rhee 2004) (Table 1). Hexahydro-3-(phenylmethyl) pyrrolo[1,2-a] pyrazine-1,4-dione (peak 13) was cyclodipeptide c-(DPro-L-Phe) or c-(L-Pro-L-Phe), which was isolated from Bacillus sp. N strain and showed to be inhibitory against Pseudomonas sp. at a MIC (minimal inhibitory concentration) of 32-64 $\mu \mathrm{g} \mathrm{mL}^{-1}$ (Kumar et al. 2013), suggesting that the antagonistic effect from Alcaligenes sp. against Pseudomonas sp. was partly attributed to the cyclodipeptides c-(D-Pro-L-Phe) and c-(L-Pro-L-Phe). To test this possibility, we undertook the purification process for the inhibitory activity against Pseudomonas sp. ZS1 (see "Materials and methods"). The purified compound was subsequently subjected to ${ }^{1} \mathrm{H}$ and ${ }^{13} \mathrm{C}$ NMR spectroscopic analysis.

Structure determination of the compound 1 (Fig. 3c): white powder; $\mathrm{C}_{14} \mathrm{H}_{16} \mathrm{~N}_{2} \mathrm{O}_{2}$; ESI-MS $m / z$ : $244[\mathrm{M}+\mathrm{H}]^{+}$; ${ }^{1} \mathrm{H}$ NMR $\left(\mathrm{CDCl}_{3}, 500 \mathrm{MHz}\right) \delta_{\mathrm{H}}: 7.34(2 \mathrm{H}, \mathrm{dd}, \mathrm{J}=7.5$, $9 \mathrm{~Hz}), 7.26(1 \mathrm{H}, \mathrm{t}, \mathrm{J}=9 \mathrm{~Hz}), 7.23(2 \mathrm{H}, \mathrm{d}, \mathrm{J}=7.5 \mathrm{~Hz})$, $5.88(1 \mathrm{H}, \mathrm{S}), 4.29(1 \mathrm{H}, \mathrm{dd}, \mathrm{J}=2.5,7.5 \mathrm{~Hz}), 4.05(1 \mathrm{H}, \mathrm{t}$, $\mathrm{J}=7.5 \mathrm{~Hz}), 3.61(2 \mathrm{H}, \mathrm{m}), 3.58(1 \mathrm{H}), 2.80(1 \mathrm{H}, \mathrm{dd}, \mathrm{J}=10.0$, $14.5 \mathrm{~Hz}), 2.32(1 \mathrm{H}, \mathrm{m}), 1.99(1 \mathrm{H}, \mathrm{m}), 1.89(2 \mathrm{H}, \mathrm{m}) ;{ }^{13} \mathrm{C}$ NMR $\left(\mathrm{CDCl}_{3}, 125 \mathrm{MHz}\right): 169.5,165.1,135.9,129.2$, 129.1, 127.5, 59.1, 56.2, 45.4, 36.8, 28.3, 22.5. Based on the NMR spectroscopic analysis of c-(L-Pro-L-Phe) by Kumar et al. (Kumar et al. 2013), the compound 1 from ZS10 was identified as cyclodipeptide c-(L-Pro-L-Phe), which exhibited a potent inhibitory activity against ZS1 at a MIC of $32 \mu \mathrm{g} \mathrm{mL} L^{-1}$ against ZS1 (see "Materials and methods").

\section{Gravimetric analysis of oil degradation by ZS1 strain is disrupted by the presence of $\mathrm{CT} 10$ strain}

To investigate if efficiency of oil degradation by ZS1 strain would be affected in presence of Alcaligenes sp. CT10, the oil degradation experiments were performed

(See figure on next page.)

Fig. 3 GC-MS analysis of compounds extracted from supernatant of Alcaligenes sp. CT10 culture. a Total ion chromatograph. Peaks with matched molecules are numbered. b MS spectra of individual compounds indicated. $\mathbf{c}$ An inhibitory compound to ZS1 from CT10. NMR analysis indicates that the compound 1 is the cyclodipeptide c-(L-Pro-L-Phe) 


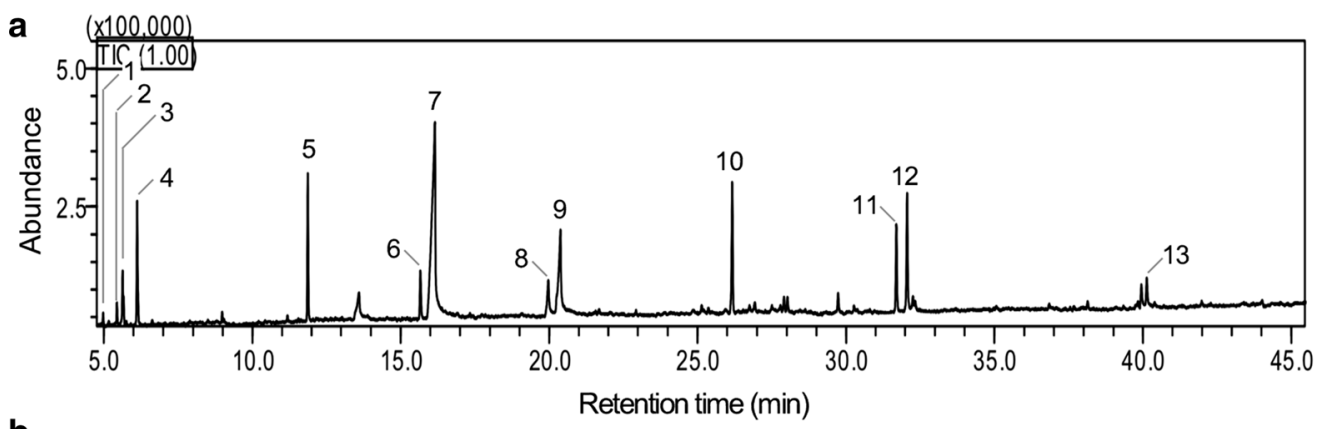

b
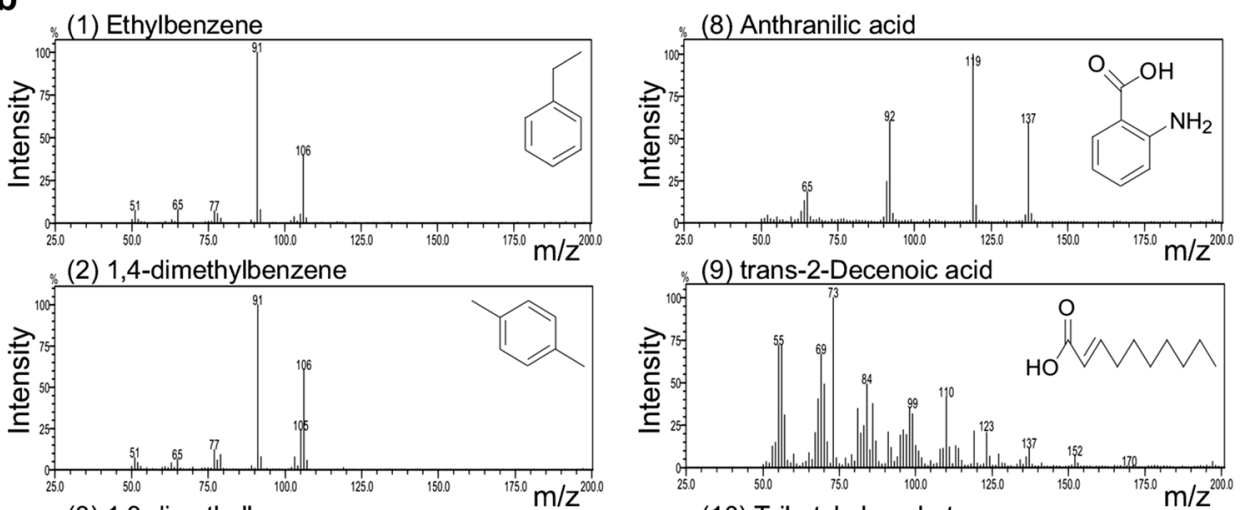

(3) 1,3-dimethylbenzene
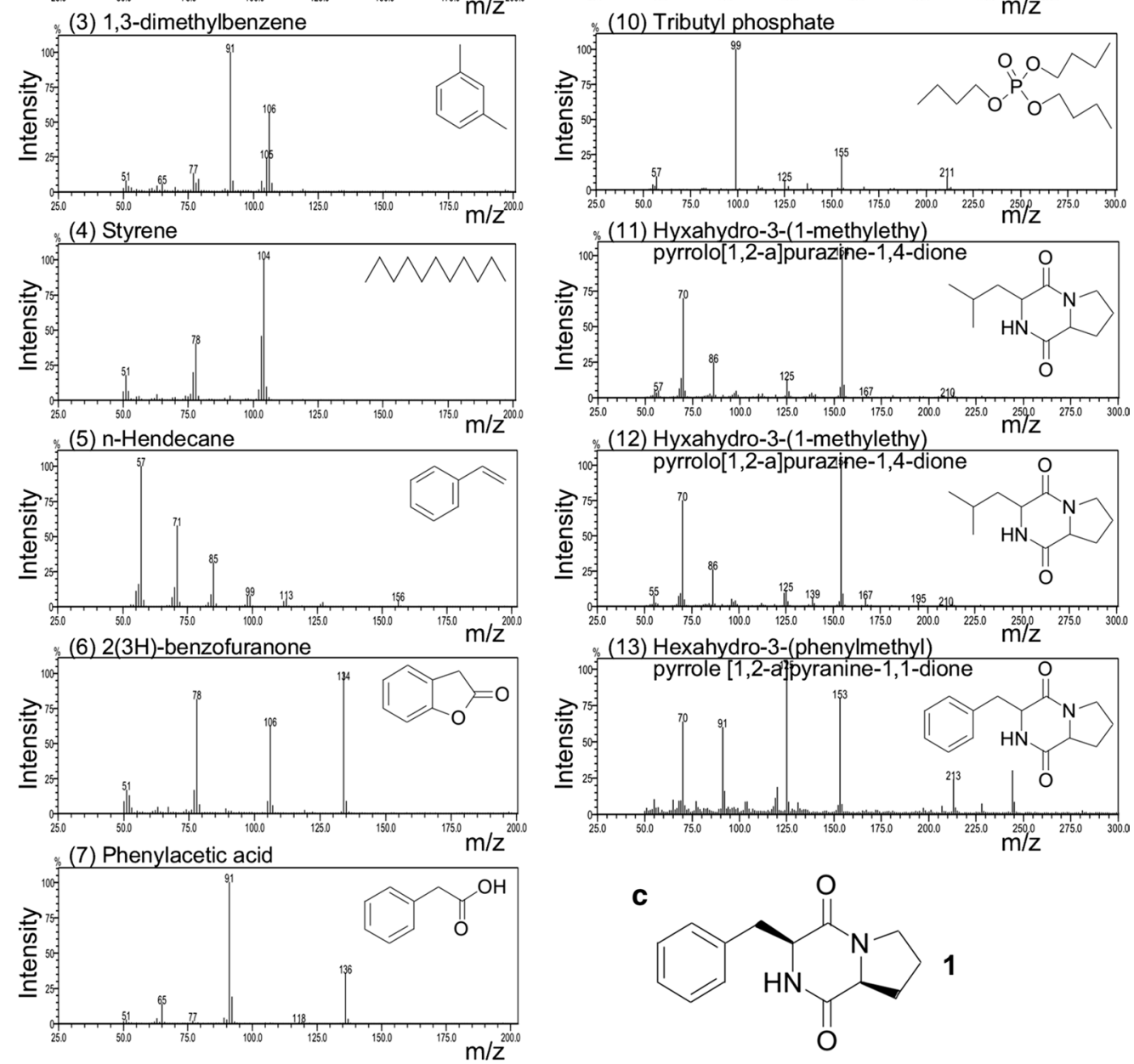

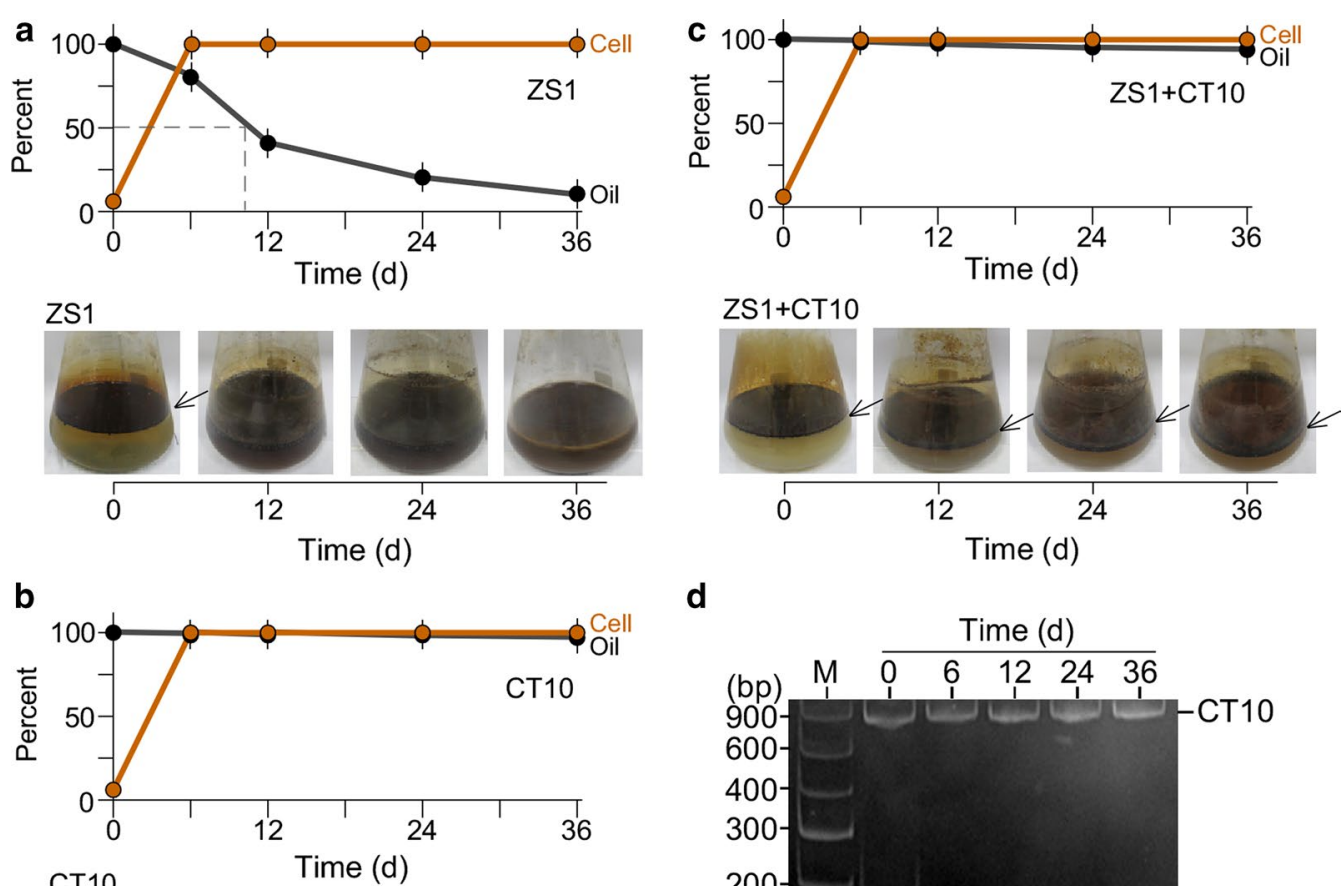

d
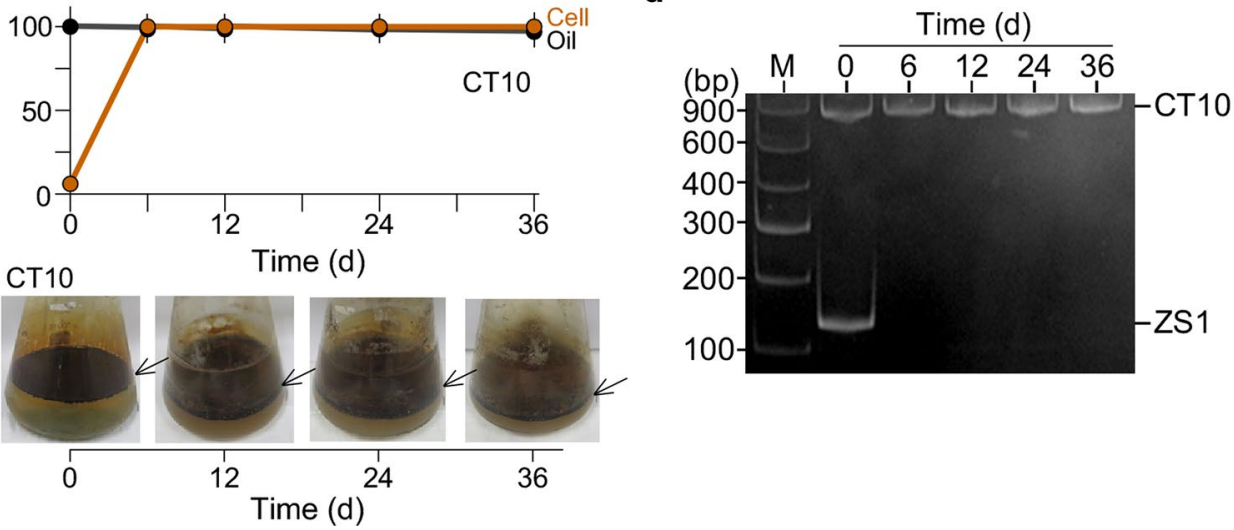

Time (d)

Fig. 4 Oil-eating activity of Pseudomonas sp. ZS1 is impeded in the presence of Alcaligenes sp. CT10. Arrow indicates the presence of floating oil on the surface of cultures. a Change of cell mass and crude oil quantity in ZS1 culture. Upper panel shows the percentage of cell mass (Cell) and crude oil mass (Oil) detected in cultures at various time points indicated. Bottom panel shows the presence (with arrow) or absence (without arrow) of floating oil in culture flask. The $50 \%$ reduction of crude oil occurs at 10 days after growth. b Change of cell mass and crude oil quantity in CT10 culture. The display is identical to a. c Change of cell mass and crude oil quantity in ZS1 and CT10 mixed culture. The display is identical to $\mathbf{a}$. $\mathbf{d}$ Dynamic change of ZS1 and CT10 populations in mixed culture indicated in (c)

in MS medium supplemented with $1 \%$ crude oil (see "Materials and methods"). Oil residues remained in the medium at various time points during growth was determined gravimetrically by using hexane extraction and weighted after evaporation (see "Materials and methods"). We found that $50 \%$ of oils was degraded in ZS1 culture 10 days after growth (Fig. 4a). On the other hand, there was hardly any oil degradation activity detected in culture of Alcaligenes sp. CT10 (Fig. 4b). However, oil degradation ability of ZS1 strains was nearly abolished when CT10 strain was present in the culture (Fig. 4c). mT-RFLP analysis confirmed that ZS1 failed to grow in presence of CT10 (Fig. 4d). These results indicated that antagonisms against oil-eating microbes could abolish its oil degradation activity.

\section{GC-MS analysis of oil degradation by ZS1 strain is impeded by the presence of $\mathrm{CT} 10$ strain}

Based on the GC-MS analysis, the crude oils used in this study were found to contain 23 linear aliphatic

(See figure on next page.)

Fig. 5 GC analysis of crude oil degradation in culture of Pseudomonas sp. ZS1 in presence or absence of Alcaligenes sp. CT10. a GC analysis of hexane extract derived from medium 36 days after shaking without bacteria. A GC spectrum of crude oil in medium is shown. $\mathbf{b}$ Linear and branched aliphatic hydrocarbons $\mathrm{C}_{17} \mathrm{H}_{36}$ detected. Left panel shows an enlarged image of the Fig. $5 \mathrm{a}$. MS spectra of the linear (upper right penal) and branched (bottom right panel) $\mathrm{C}_{17} \mathrm{H}_{36}$ are shown. c A GC spectrum of oils in ZS1 culture at $36 \mathrm{~d}$ after growth. An inset shows the branched $\mathrm{C}_{17} \mathrm{H}_{36}$ but not linear $\mathrm{C}_{17} \mathrm{H}_{36}$ remained noticeable. d A GC spectrum of oils in $\mathrm{CT} 10$ culture at 36 days after growth. e A GC spectrum of oils in mixed CT10 and ZS1 culture at 36 days after growth 

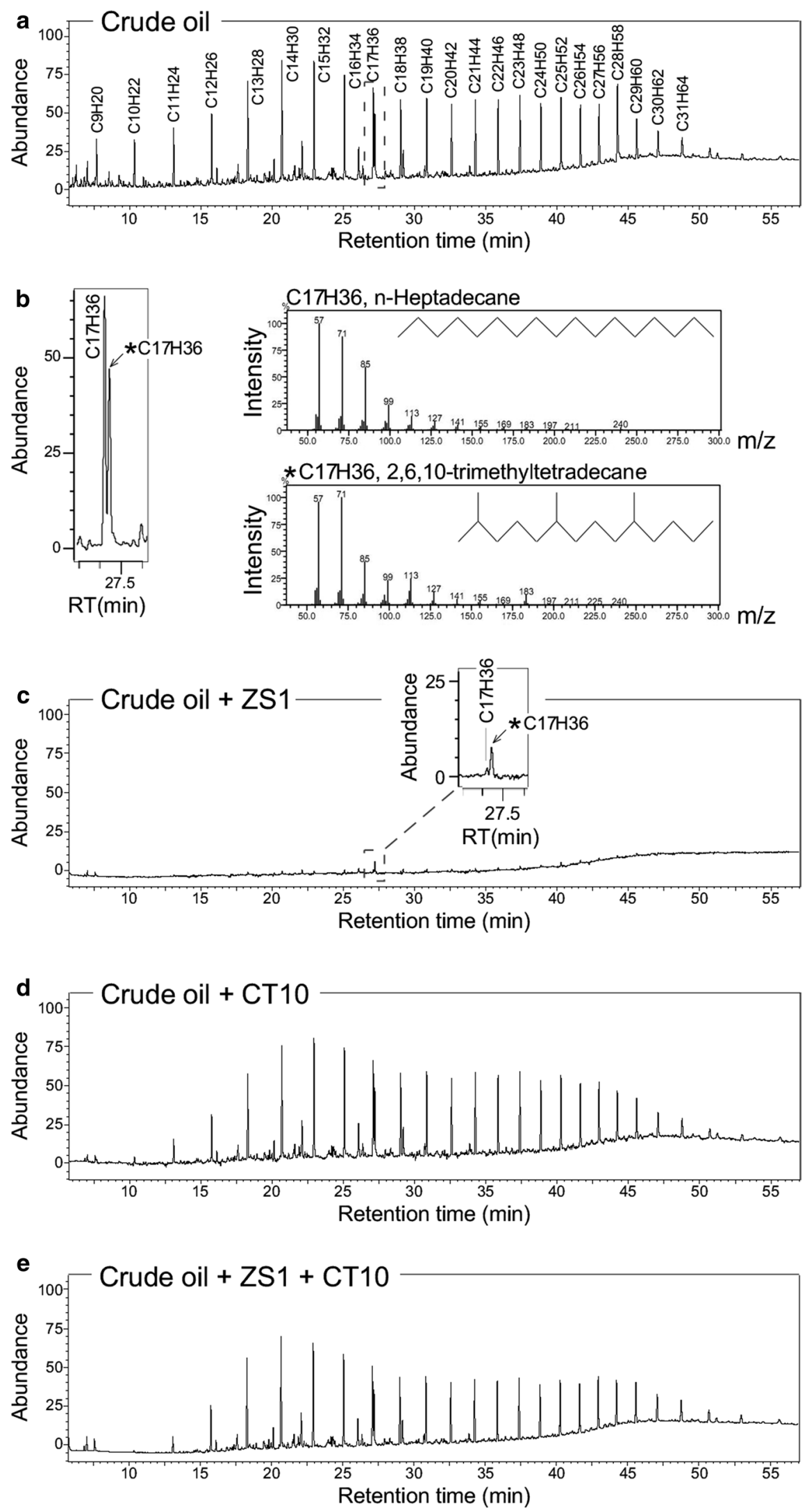
Table 2 Degradation of crude oil in cultures of one or both of Alcaligenes sp. CT10 and Pseudomonas sp. ZS1

\begin{tabular}{|c|c|c|c|c|c|c|c|c|}
\hline $\mathrm{LAH}(\mathrm{C} \#)^{\mathrm{a}}$ & $\mathrm{RT}(\min )^{\mathrm{b}}$ & Ctl (level) ${ }^{c}$ & CT10 (level) $^{d}$ & CT10/ZS1 (level) $^{\mathbf{e}}$ & ZS1 (level) ${ }^{f}$ & CT10 (\%deg) & CT10/ZS1 (\%deg) ${ }^{h}$ & ZS1 (\%deg) ${ }^{i}$ \\
\hline 9 & 7.68 & 8570 & 0 & 0 & 0 & 100.00 & 100.00 & 100.00 \\
\hline 10 & 10.34 & 9518 & 1810 & 393 & 0 & 80.98 & 95.87 & 100.00 \\
\hline 11 & 13.09 & 11,662 & 4742 & 3503 & 0 & 59.34 & 69.96 & 100.00 \\
\hline 12 & 15.76 & 14,531 & 9192 & 9351 & 0 & 36.74 & 35.65 & 100.00 \\
\hline 13 & 18.29 & 20,599 & 17,001 & 18,330 & 453 & 17.47 & 11.02 & 97.80 \\
\hline 14 & 20.68 & 23,975 & 22,193 & 22,858 & 598 & 7.43 & 4.66 & 97.51 \\
\hline 15 & 22.94 & 26,059 & 25,468 & 22,826 & 664 & 2.27 & 12.41 & 97.45 \\
\hline 16 & 25.07 & 21,935 & 21,923 & 19,366 & 777 & 0.05 & 11.71 & 96.46 \\
\hline 17 & 27.09 & 21,009 & 20,503 & 17,364 & 309 & 2.41 & 17.35 & 98.53 \\
\hline 18 & 29.02 & 16,658 & 16,654 & 14,154 & 0 & 0.02 & 15.03 & 100.00 \\
\hline 19 & 30.85 & 16,659 & 16,722 & 15,411 & 300 & -0.38 & 7.49 & 98.20 \\
\hline 20 & 32.59 & 16,032 & 15,933 & 13,415 & 592 & 0.62 & 16.32 & 96.31 \\
\hline 21 & 34.26 & 16,938 & 17,050 & 13,738 & 547 & -0.66 & 18.89 & 96.77 \\
\hline 22 & 35.85 & 16,626 & 16,535 & 13,159 & 378 & 0.55 & 20.85 & 97.73 \\
\hline 23 & 37.38 & 17,060 & 17,005 & 13,042 & 624 & 0.32 & 23.55 & 96.34 \\
\hline 24 & 38.85 & 15,283 & 15,178 & 11,839 & 428 & 0.69 & 22.53 & 97.20 \\
\hline 25 & 40.27 & 15,747 & 15,757 & 12,688 & 658 & -0.06 & 19.43 & 95.82 \\
\hline 26 & 41.63 & 14,552 & 14,426 & 11,597 & 447 & 0.87 & 20.31 & 96.93 \\
\hline 27 & 42.94 & 13,404 & 13,273 & 12,236 & 532 & 0.98 & 8.71 & 96.03 \\
\hline 28 & 44.23 & 20,840 & 11,537 & 10,560 & 694 & 44.64 & 49.33 & 96.67 \\
\hline 29 & 45.58 & 10,534 & 10,344 & 10,563 & 723 & 1.80 & -0.28 & 93.14 \\
\hline 30 & 47.08 & 7432 & 7411 & 7377 & 0 & 0.28 & 0.74 & 100.00 \\
\hline 31 & 48.77 & 6251 & 6117 & 6643 & 0 & 2.14 & -6.27 & 100.00 \\
\hline Total LAH. & & 361,874 & 316,774 & 280,413 & 8724 & 12.5 & 22.5 & 97.6 \\
\hline Total oil & & 481,954 & 428,608 & 374,615 & 13,911 & 11.1 & 22.3 & 97.1 \\
\hline
\end{tabular}

a $\mathrm{LAH}$ (C\#) for linear aliphatic hydrocarbons with carbon numbers

${ }^{b}$ RT for retention time in minute

c ctl (level) for levels in control

d CT10 (level) for levels in Alcaligenes sp. culture

e CT10/ZS1 (level) for levels in mixed Alcaligenes sp. and Pseudomonas sp. cultures, respectively

${ }^{f}$ ZS1 (level) for levels in Pseudomonas sp. culture

${ }^{g} \mathrm{CT} 10$ (\%deg) for oil degradation rate in Alcaligenes sp. culture

h CT10/ZS1 (\%deg) for oil degradation rate in mixed Alcaligenes sp. and Pseudomonas sp. culture

i ZS1 (\%deg) for oil degradation rate in Pseudomonas sp. culture

hydrocarbons ranged from C9 to C31 (Additional file 1: Figure S3). Crude oils in supernatant of various cultures 36 days after growth were hexane extracted for GC analysis (see "Materials and methods"). Oils recovered 36 days after incubation in medium without bacteria was used as control for initial levels of various hydrocarbon molecules (Fig. 5a). We noted that a residue of branched aliphatic hydrocarbon $n$-heptadecane present in the crude oil (Fig. 5b). Based on GC analysis, we found that $97.4 \%$ of crude oils were degraded in culture of Pseudomonas sp. ZS1 36d after growth, though a trace amount of branched hydrocarbon $n$-heptadecane remained to be detected (Fig. 5c, Table 2).
On the other hand, oils were reduced by $12.5 \%$ compared to the control levels in culture of Alcaligenes sp. CT10 36d after growth (Fig. 5d, see Table 2). However, degradation rate of some hydrocarbons such as C9, $\mathrm{C} 10, \mathrm{C} 11$, and $\mathrm{C} 28$ was high (degradation rate $>35 \%$ ). In a mixed culture of ZS1 and CT10, we found that $22.5 \%$ of total oils were degraded 36d after growth (Fig. 5e, see Table 2), much lower than that of $97.6 \%$ degradation in ZS1 culture, though a bit higher than that of $12.5 \%$ in CT10 culture. These results were in agreement with the gravimetric analysis that crude-oil degradation ability of Pseudomonas sp. ZS1 strain could be inhibited in presence of Alcaligenes sp. CT10. 


\section{Discussion}

Enhanced bioremediation is believed to be a useful method for oil pollutant cleanup (Patowary et al. 2016; El-Bestawy et al. 2014). However, there are limitations (Díaz-Ramírez et al. 2003; Venosa and Zhu 2003). Physical and chemical conditions are known to affect the growth of the oil-eating microorganisms at pollutant sites. In this study, we show that biotic factors such as antagonistic species can also influence the growth of the oil-eating microorganisms (see Figs. 4, 5). Hence, oil degradation during enhanced bioremediation can be complicated by not only physical and chemical factors, but also biological factors.

We have previously screened for biosurfactant-producing microorganisms using the mT-RFLP methodology to monitor the enrichment under selective growth conditions. In this study, we show that by using this method, antagonism between microbes is readily detected (see Figs. 1, 2). All major populations observed in mixed culture of the oil sludge-originating microorganisms are found to be involved in one of the antagonistic interactions, implying that antagonism between microbes is not ignorable in environmental niches.

Biosurfactant rhamnolipid is known to inhibit bacteria such as Serratia marcescens, Enterobacter aerogenes, and Klebsiella pneumoniae (Haba et al. 2003). In this study, we show that rhamnolipid produced by Pseudomonas sp. ZS1 inhibits the growth of Donghicola sp. CT5 and Bacillus sp. CT6 (see Additional file 1: Figure S2). It is possible that in a bacterial consortium for bioremediation (Patowary et al. 2016; El-Bestawy et al. 2014), the growth of oil-eating microorganisms could be inhibited by other biosurfactant-producing microbes. In fact, it has been observed that microbial populations change during bioremediation (MacNaughton et al. 1999). Hence, realtime monitoring the change of microbial populations during bioremediation would permits rapid intervention for improving oil-eating bacterial growth and thus increasing the efficiency of oil pollutant cleanup.

In this study, we show that Alcaligenes sp. exhibits antagonistic activity against Pseudomonas sp. (see Fig. 2). Based on the GC-MS analysis, a number of bioactive compounds are found to be produced by CT10 (see Table 1). In particular, we have purified the compound 1, known as cyclodipeptide c-(L-Pro-L-Phe) that shows a potent inhibitory activity against ZS1 at a MIC of $32 \mu \mathrm{g} \mathrm{mL}^{-1}$.

Cyclodipeptides (CDPs) or 2,5-diketopiperazines (DKPs) are the smallest cyclic peptides that widely spread in nature as secondary functional metabolites or side products of protein metabolism in microorganisms, plants, and animals (Borthwick 2012; Prasad 1995). CDPs are primarily synthesized by the non-ribosomal peptide synthetases (Schwarzer et al. 2003) and cyclodipeptide synthases (Gondry et al. 2009) in microorganisms. They often serve as precursors for modification with various tailoring enzymes that result diverse compounds with numerous bioactivities such as thaxtomin A and gliotoxin. Thaxtomin A is derived from hydroxylation of precursor c-(L-Trp-L-Phe) (Healy et al. 2002), whereas gliotoxin is generated through oxidation, sulfurization, and methylation of precursor c-(L-Phe-L-Ser) (Gardiner and Howlett 2005). Thus, CDPs have shown great potential for new drug development (Borthwick 2012).

Holden et al. (1999) have proposed that CDPs interfere quorum sensing signals in bacteria and hence affect bacterial growth. However, this ideal is challenged by Campbell et al. (2009) whom have shown that none of the CDPs tested exhibit activation or inhibition of quorum sensing signals. Hence, the mechanisms for CDPs to inhibit bacterial growth remain elucidation.

Based on GC analysis, we find that degradation rate of crude oil by Pseudomonas sp. ZS1 reaches as high as 97.6\% (see Fig. 5, Table 2) in 36d. However, when Alcaligenes sp. CT10 is present, the degradation rate reduces by 4.3 -fold (degradation rate of $22.5 \%$ vs. $97.6 \%$ ). Degradation of selected hydrocarbons such as C9, C10, C11, and C28 by CT10 is observed, suggesting a complex of hydrocarbon degradation by various environmental microorganisms.

\section{Additional file}

Additional file 1: Figure S1. Growth curve analysis of four strains isolated from oil-sludge. Figure S2. Pseudomonas sp. ZS1 antagonizes against Donghicola sp. CT5 and Bacillus sp. CT6. Figure S3. GC-MS analysis of crude oil compositions used in this study.

\section{Abbreviations}

GC-MS: gas chromatography coupled with mass spectrometry; mT-RFLP: modified terminal-labeled restriction fragment length polymorphism; NMR: nuclear magnetic resonance.

\section{Authors' contributions}

JLiang, TC, and YH carried out the biological and chemical studies; JLiu conceived of the study, participated in its design and coordination, and draft the manuscript. All authors read and approved the final manuscript.

\section{Author details}

${ }^{1}$ Ocean College, Zhejiang University, Marine Science Building \#379, Zhoushan Campus, 1 Zheda Road, Dinghai District, Zhoushan 316000, ZJ, China. ${ }^{2}$ Ocean Research Center of Zhoushan, Zhejiang University, Zhoushan 316021, ZJ, China.

\section{Acknowledgements}

The authors would like to thank Mr. G. Zheng and J. Xiao for assistance in collection of the petroleum sludge in the San-Jiang Ferry Terminal, Zhoushan Islands, Zhejiang Province, China.

Competing interests

The authors declare that they have no competing interests. 


\section{Consent for publication}

All authors have read and agreed to submit to AMB Express for publication.

\section{Ethics approval and consent to participate}

This study does not contain materials derived from human or animal.

\section{Funding}

This work was partly supported by Zhoushan Municipal Science and Technology Bureau, Zhejiang Province, China (Grants numbers: 2014C51020 and 2016C51026) and Zhejiang Dong-Jie Biological Science and Technology LLC, Zhejiang Province, China (K18-529102-006) to JLiu.

\section{Publisher's Note}

Springer Nature remains neutral with regard to jurisdictional claims in published maps and institutional affiliations.

Received: 31 March 2018 Accepted: 23 May 2018

Published online: 28 May 2018

\section{References}

Al-Mailem DM, Al-Deieg M, Eliyas M, Radwan SS (2017) Biostimulation of indigenous microorganisms for bioremediation of oily hypersaline microcosms from the Arabian Gulf Kuwaiti coasts. J Environ Manag 193:576-583

Bertani G (1951) Studies on lysogenesis. I. The mode of phage liberation by Iysogenic Escherichia coli. J Bacteriol 62(3):293-300

Bharali P, Das S, Konwar BK, Thakur AJ (2011) Crude biosurfactant from thermophilic Alcaligenes faecalis: feasibility in petro-spill bioremediation. Int Biodeterior Biodegradation 65:682-690

Borthwick AD (2012) 2,5-Diketopiperazines: synthesis, reactions, medicinal chemistry, and bioactive natural products. Chem Rev 112(7):3641-3716. https://doi.org/10.1021/cr200398y

Campbell J, Lin Q, Geske GD, Blackwell HE (2009) New and unexpected insights into the modulation of LuxR-type quorum sensing by cyclic dipeptides. ACS Chem Biol 4(12):1051-1059. https://doi.org/10.1021/ cb900165y

Cheng T, Liang J, He J, Hu X, Ge Z, Liu J (2017) A novel rhamnolipid-producing Pseudomonas aeruginosa ZS1 isolate derived from petroleum sludge suitable for bioremediation. AMB Express 7(1):120. https://doi.org/10.1186/ s13568-017-0418-x

Díaz-Ramírez IJ, Gutiérrez-Rojas M, Ramírez-Saad H, Favela-Torres E (2003) Biodegradation of Maya crude oil fractions by bacterial strains and a defined mixed culture isolated from Cyperus laxus rhizosphere soil in a contaminated site. Can J Microbiol 49:755-761. https://doi.org/10.1139/ w03-098

El-Bestawy E, Sabir J, Mansy AH, Zabermawi N (2014) Comparison among the efficiency of different bioremediation technologies of atrazine-contaminated soils. J Bioremed Biodeg 5(5):237. https://doi.org/10.4172/21556199.1000237

Fan J, Xie Y, Xue J, Li B (2008) Isolation and identification of toxins inhibiting Dentrolimus tabulaeformis from an antagonistic strain of Beauveria. Wei Sheng Wu Xue Bao 48(5):596-601

Fang J, Liu Y, Wang W, Xie W, Fang S, Han H (2005) The anti-endotoxic effect of o-aminobenzoic acid from Radix isatidis. Acta Pharmacol Sin 26:593-597

Fleming A (1929) On the antibacterial action of cultures of a Penicillium, with special reference to their use in the isolation of $B$. influenzae. Brit J Exp Pathol 10:226-236

Gardiner DM, Howlett BJ (2005) Bioinformatic and expression analysis of the putative gliotoxin biosynthetic gene cluster of Aspergillus fumigatus. FEMS Microbiol Lett 248(2):241-248. https://doi.org/10.1016/j.femsl e.2005.05.046

Gondry M, Sauguet L, Belin P, Thai R, Amouroux R, Tellier C, Tuphile K, Jacquet M, Braud S, Courcon M, Masson C, Dubois S, Lautru S, Lecoq A, Hashimoto S, Genet R, Pernodet JL (2009) Cyclodipeptide synthases are a family of tRNA-dependent peptide bond-forming enzymes. Nat Chem Biol 5(6):414-420. https://doi.org/10.1038/nchembio.175
Haba E, Pinazo A, Jauregui O, Espuny MJ, Infante MR, Manresa A (2003) Physicochemical characterization and antimicrobial properties of rhamnolipids produced by Pseudomonas aeruginosa 47T2 NCBIM 40044. Biotechnol Bioeng 81(3):316-322. https://doi.org/10.1002/bit.10474

Healy FG, Krasnoff SB, Wach M, Gibson DM, Loria R (2002) Involvement of a cytochrome $\mathrm{P} 450$ monooxygenase in thaxtomin A biosynthesis by Streptomyces acidiscabies. J Bacteriol 184(7):2019-2029

Holden MT, Ram Chhabra S, de Nys R, Stead P, Bainton NJ, Hill PJ, Manefield M, Kumar N, Labatte M, England D, Rice S, Givskov M, Salmond GP, Stewart GS, Bycroft BW, Kjelleberg S, Williams P (1999) Quorum-sensing cross talk: isolation and chemical characterization of cyclic dipeptides from Pseudomonas aeruginosa and other gram-negative bacteria. Mol Microbiol 33(6):1254-1266

Holliger C, Gaspard S, Glod G, Heijman C, Schumacher W, Schwarzenbach RP, Vazquez F (1997) Contaminated environments in the subsurface and bioremediation: organic contaminants. FEMS Microbiol Rev 20(3-4):517-523

Kanaly RA, Harayama S (2010) Advanced in the field of high-molecular-weight polycyclic aromatic hydrocarbon biodegradation by bacteria. Microb Biotechnol 3:136-164

Karamalidis AK, Evangelou AC, Karabika E, Koukkou Al, Drainas C, Voudrias EA (2010) Laboratory scale bioremediation of petroleum-contaminated soil by indigenous microorganisms and added Pseudomonas aeruginosa strain. Bioresour Technol 101:6545-6552

Kumar N, Mohandas C, Nambisan B, Kumar DR, Lankalapalli RS (2013) Isolation of proline-based cyclic dipeptides from Bacillus sp. N strain associated with rhabditid [corrected] entomopathogenic nematode and its antimicrobial properties. World J Microbiol Biotechnol 29(2):355-364. https:// doi.org/10.1007/s11274-012-1189-9

Liu WT, Marsh TL, Cheng H, Forney LJ (1997) Characterization of microbial diversity by determining terminal restriction fragment length polymorphisms of genes encoding 16S rRNA. Appl Environ Microbiol 63(11):4516-4522

MacNaughton SJ, Stephen JR, Venosa AD, Davis GA, Chang Y, White DC (1999) Microbial population changes during bioremediation of an experimental oil spill. Appl Biochem Biotechnol 65:3566-3574

Moreno C, Romero J, Espejo RT (2002) Polymorphism in repeated 16S rRNA genes is a common property of type strains and environmental isolates of the genus Vibrio. Microbiology 148(Pt 4):1233-1239. https://doi. org/10.1099/00221287-148-4-1233

Murphy M, Alkhalidi M, Crocker J, Lee S, Oregan P, Acott P (2005) Two formulations of the industrial surfactant, Toximul, differentially reduce mouse weight gain and hepatic glycogen in vivo during early development: effects of exposure to Influenza B Virus. Chemosphere 59(2):235-246

Patowary K, Patowary R, Kalita MC, Deka S (2016) Development of an efficient bacterial consortium for the potential remediation of hydrocarbons from contaminated sites. Front Microbiol 7:1092. https://doi.org/10.3389/fmicb 2016.01092

Prasad C (1995) Bioactive cyclic dipeptides. Peptides 16(1):151-164

Rhee KH (2004) Cyclic dipeptides exhibit synergistic, broad spectrum antimicrobial effects and have anti-mutagenic properties. Int J Antimicrob Agents 24(5):423-427. https://doi.org/10.1016/j.ijantimicag.2004.05.005

Schwarzer D, Finking R, Marahiel MA (2003) Nonribosomal peptides: from genes to products. Nat Prod Rep 20(3):275-287

Singh-Babak SD, Babak T, Diezmann S, Hill JA, Xie JL, Chen YL, Poutanen SM, Rennie RP, Heitman J, Cowen LE (2012) Global analysis of the evolution and mechanism of echinocandin resistance in Candida glabrata. PLOS Pathog 8(5):e1002718. https://doi.org/10.1371/journal.ppat.1002718

Vaneechoutte M, De Beenhouwer H, Claeys G, Verschraegen G, De Rouck A, Paepe N, Elaichouni A, Portaels F (1993) Identification of Mycobacterium species with amplified rDNA restriction analysis. J Clin Microbiol 31:2061-2065

Varjani SJ, Upasani VN (2016) Biodegradation of petroleum hydrocarbons by oleophilic strain of Pseudomonas aeruginosa NCIM 5514. Bioresour Technol 222:195-201. https://doi.org/10.1016/j.biortech.2016.10.006

Venosa AD, Zhu X (2003) Biodegradation of crude oil contaminating marine shorelines and freshwater wetlands. Spill Sci Technol Bull 8:163-178. https //doi.org/10.1016/S1353-2561(03)00019-7 
Waksman SA, Woodruff HB (1940) The soil as a source of microorganisms antagonistic to disease-producing bacteria. J Bacteriol 40:581-600

Yan PS, Song Y, Sakuno E, Nakajima H, Nakagawa H, Yabe K (2004) Cyclo(Lleucyl-L-prolyl) produced by Achromobacter xylosoxidans inhibits aflatoxin production by Aspergillus parasiticus. Appl Environ Microbiol 70(12):7466-7473. https://doi.org/10.1128/AEM.70.12.7466-7473.2004

Zajic E, Supplison B (1972) Emulsification and degaradation of "Bunker C"fuel oil by microorganisms. Biotechnol Bioeng 14:331-334
Zhang Y, Miller RM (1992) Enhanced octadecane dispersion and biodegradation by a Pseudomonas rhamnolipid surfactant (biosurfactant). Appl Environ Microbiol 58(10):3276-3282

Zhu Y-J, Zhou H-T, Hu Y-H, Tang J-Y, Su M-X, Guo Y-J, Chen Q-X, Liu B (2011) Antityrosinase and antimicrobial activities of 2-phenylethanol, 2-phenylacetaldehyde and 2-phenylacetic acid. Food Chem 124:298-302

\section{Submit your manuscript to a SpringerOpen ${ }^{\odot}$ journal and benefit from:}

- Convenient online submission

- Rigorous peer review

- Open access: articles freely available online

- High visibility within the field

- Retaining the copyright to your article

Submit your next manuscript at $\boldsymbol{\nabla}$ springeropen.com 